\title{
Research Article \\ SCREENING OF CUCUMBER GERMPLASMS FOR HIGH TEMPERATURE AND LONG DAY PHOTOPERIODIC TOLERANCE
}

\author{
S. M. Shakya, S. P. Bhattarai, K. M. Tripathi and M. D. Sharma \\ Institute of Agriculture and Animal Sciences, Rampur, Chitwan, Nepal
}

\begin{abstract}
A total of 139 cucumber germplasms collected from within the country and abroad were sown on May 15 and 29, 2000 on single row observation at Horticulture Farm, Lamjung Campus, Lamjung and Yampaphant, Tanahun, respectively. The germplasms varied widely in leaf color, duration of producing the first male and female flowers after sowing, number of node bearing first male and female flowers, number of nodes and branches per plant, sex ratio, number of female flowers and fruits per plant, yield per plant and market acceptability of the fruits at both sites. Altogether, 25 entries produced fruits at Yampaphant. Of them, the entry collected from Makwanpur (seed distributed by the Plan Office) and the next entry collected from Dhankuta and named Dhankuta Local produced the highest fruit yield of 4.69 and $4.50 \mathrm{~kg} / \mathrm{plant}$, respectively. At Lamjung site, the entry named Mahyco Green Long produced the highest yield of $1.77 \mathrm{~kg} / \mathrm{plant}$ followed by Bhaktapur Local with $1.67 \mathrm{~kg} /$ plant. Only ten entries produced yield at both sites. Of them, the entry collected from Suryapur of Chitwan gave the highest yield of 2.59 and $1.17 \mathrm{~kg} / \mathrm{plant}$ at Yampaphant and Lamjung, respectively. Hence, these collections were found the most promising with high tolerance to high temperature and long day photoperiod condition as compared to other entries.
\end{abstract}

Key words: Cucumber germplasm, screening, high temperature, long day

\section{INTRODUCTION}

Cucumber, one of the most important members of cucurbits in Nepal, is very popular among Nepalese consumers as it is used in various forms, such as salad, pickle and cooked vegetable. At present, it has subsistence as well as commercial importance, but it is a potential crop for processing in the future (Shrestha and Ghimire, 1996). It has high potential for increased productivity and income generation as well.

It is basically a summer season crop grown both in the hills and Terai region of Nepal. However during this time of the year, the yields of the commercial varieties are extremely low because of environmental stresses, such as high temperature, high rainfall and long day photoperiod. Such conditions promote maleness excessively (Seshadri, 1990; LARC, 1997). Most of the research works related to varieties conducted in different government and NARC farms have shown that commercial varieties such as Green Long and Poinsett for Terai, and Kusle and Bhaktapur Local for the hills are suitable for fresh fruit production during March-April (Pandey and Adhikari, 1996). The performance of these varieties when planted in other months of the year remained poorer because of preponderance of maleness in summer months (May-September) and chilling stress in winter months (October-February), thus rendering uneconomical production (Subedi et al., 1997). Actually, there has been no study regarding the sex dynamics and the quantitative effect of the environment, i.e. different season of the year. Such study would have been the basis for manipulation of the sex and its expression for production through various means including genetic recombination or other technique, such as exogenous application of plant growth regulators (Chaudhary, 1987).

One of the approaches for overcoming the heat, rain and light induced stress especially during May-September could be tolerant or resistant lines from the pool of genetic variations. There are reports indicating the prevalence of genetic variations for such selections (LARC, 1997; Nonnecke, 1989; Seshadri, 1990; Subedi et al., 1997). However, studies on wider collection and screening of germplasm including indogenous as well as exotic are lacking in Nepal. Thus, identification of appropriate land races for this period, i.e. those producing higher number of female flowers and thereby better yield, would help solve the problem. Keeping this in mind, the present study was carried out with the objectives of morphological characterization of the cucumber germplasms collected from Nepal and abroad, and identifying the slicing type cucumber varieties tolerant to high temperature, high rainfall and long day photoperiodic condition suitable for summer planting in the river basin, low hills and mid hills of Nepal. 


\section{MATERIALS AND METHODS}

A wide range of cucumber germplasms collected from within the country and abroad were placed on single row observation in two major agro-ecological zones, i.e. Lamjung Campus, Sunderbazar, which represents lower hills $(750 \mathrm{~m}$ asl) and Yampaphant, outreach site of IAAS in Tanahun, which represents river basin area ( $450 \mathrm{~m}$ asl). The weather data of these sites are presented in Figure 1. The monthly mean maximum temperature during summer-rainy season was slightly higher at Yampaphant (above $30^{\circ} \mathrm{C}$ ) than at Sundarbazar (below $30^{\circ} \mathrm{C}$ ). Altogether, 139 germplasms were tested. At Lamjung, the seeds were sown in well prepared plots on $15^{\text {th }}$ May 2000 and re-sowing was done up to $29^{\text {th }}$ May 2000. Two to three seeds were sown per hill and later on one plant was maintained per hill. Thus, there was a single row of 3 plants per entry of germplasm. The spacing was 1.2 $\mathrm{m}$ between plants and between rows. Before sowing, farm yard manure@20 t/ha was applied at final land preparation. Chemical fertilizers were also used @ 120:60:50 NPK kg/ha through DAP, urea and murate of potash. Total amount of DAP and murate of potash were applied before seed sowing. Nitrogen was applied in the form of urea through four split doses at 15 days intervals, the first dose being applied 25 days after sowing. Other plant protection measures including application of micronutrients were also done as needed. The plants were staked uniformly by providing robust bamboo splits. The plots were kept weed free through manual weeding. Irrigations were done with drip system in such a way that the plot was maintained at field capacity. The fruits were harvested at marketable stage (approximately $250 \mathrm{~g}$ each). At Yampaphant also, the same procedure was applied except that the seed sowing was done on $29^{\text {th }}$ May 2000 and re-sowings were done on $4^{\text {th }}$ and $10^{\text {th }}$ of June 2000. Observations were taken on various characteristics such as morphological, flowering, maturity, fruit number per plant, fruit yield and fruit quality.

\section{RESULTS AND DISCUSSION}

\section{Yampaphant, Tanahun site}

Out of 120 entries tested at Yampaphant, the observations of only 97 entries could be obtained in terms of morphological characters, which included vegetative as well as reproductive characters. The observations on fruit yield and fruit maturity were made in 25 entries while fruit quality only in 15 entries.

\section{Leaf and tendril characters}

Table 1 shows descriptive statistics of vegetative characters of 97 entries. Number of lobes in leaf varied from 3 to 7 with a mean value of 5.3. Leaf color varied from light green to dark green. Leaf shape was mostly palmate. Leaf size was mostly medium. Leaf hair was mostly present with dense hair. Number of leaves/plant varied from 26 to 90 with a mean of 58.02 (Table 2). The tendrils were mostly simple type (Table 1).

\section{Stem and other vegetative characters}

Among 93 entries tested at Yampaphant in 2000, the main stem length ranged from 1.8 to $12.4 \mathrm{~m}$. with an average of $7.58 \mathrm{~m}$ (Table 2). The stem hair was dense (Table 1). Table 2 showed that total number of nodes/ plant varied from 26 to 90 with a mean of 57.95 and total number of branches/plant varied zero to 13 with a mean of 6.13 .

\section{Reproductive characters}

Table 2 showed that days to first male flowering after sowing varied from 42 to 89 days with 63.08 days as mean. Days to appearance of first female flower after sowing varied from 42 to 102 days with a mean of 79.48 days. Number of nodes bearing first male flower varied from 4 to 44 with 17.8 as mean, whereas such number bearing first female flower varied from 4 to 51 with 24.57 as mean. Total number of female flowers/plot varied from zero to 20 with a mean value of 4.45 . Out of 99 germplasm entries, 23 did not produce female flowers. Sex ratio (male to female flowers) also varied from total androecious to 906 with a mean value of 160.8 . The results indicated that the germplasms in the study had great variations in both morphological and reproductive characters. 
Table 1. Range and mean values of various vegetative characters of 97 collection entries of cucumber germplasms tested at Yampaphant, Tanahun, 2000

\begin{tabular}{|c|c|c|c|c|}
\hline \multicolumn{2}{|l|}{ Variables } & \multicolumn{2}{|c|}{ Range } & \multirow{2}{*}{$\begin{array}{c}\text { Mean } \\
5.3\end{array}$} \\
\hline No. of leaf lobes & 3 & - & 7 & \\
\hline Leaf color & (light green) & - & 3 (dark green) & 1.9 \\
\hline Leaf shape & - & - & & mostly palmate \\
\hline Leaf size & 1 (small) & - & 3 (Big) & 1.92 \\
\hline Tendril type & 1 (simple) & - & 2 (Bifid) & 1.03 \\
\hline Leaf hair & 1 (presence) & - & 2 (Absence) & 1.01 \\
\hline Leaf hair density & 1 (sparse) & - & 2 (Dense) & 1.94 \\
\hline Growth habit & 1 (determinate) & - & 3 (Indeterminate) & 2.93 \\
\hline Stem hair density & 1 (sparse) & - & 3 (Very dense) & 1.93 \\
\hline Canopy size & 1 (small) & - & 3 (Very big) & 1.99 \\
\hline
\end{tabular}

Table 2. Range and mean values of flower, leaf and main stem characters of cucumber collection entries tested at Yampaphant, Tahanun, 2000

\begin{tabular}{|lccc|}
\hline Variables & No. of entries observed & Range & Mean \\
\hline Days to first male flower & 99 & $42-89$ & 63.08 \\
No. of nodes at first male flower & 99 & $4-44$ & 17.80 \\
Days to first female flower & 75 & $42-102$ & 79.48 \\
No. of nodes at first female flower & 75 & $4-51$ & 24.57 \\
Total nodes/plant & 93 & $26-90$ & 57.95 \\
Total branches/plant & 93 & $0-13$ & 6.13 \\
Total female flowers/plot & 99 & $0-20$ & 4.45 \\
No. of male flowers/female flower & 99 & $0-906$ & 160.80 \\
No. of leaves/plant & 93 & $26-90$ & 58.02 \\
Main stem length (m) & 93 & $1.8-12.4$ & 7.58 \\
Flower diameter (cm) & 75 & $1.9-4.4$ & 3.38 \\
No. of petals & 82 & $5-8$ & 6.10 \\
\hline
\end{tabular}

\section{Maturity and yield characters}

All the entries did not bear fruits. Results of the maturity and yield characters of those entries bearing fruits have been presented in Table 3. Days to first harvest of the fruits varied from 70 to 118 days after seed sowing with an average of 99.44 days. Days to last harvesting of the fruits varied from 70 to 122 days with a mean of 102.48 days. The frequency of fruit harvest was 1 to 3 times with a mean of 1.48 .

Regarding fruit yield, the total number of fruits/plot ranged from 1 to 9 with a mean of 4.24 whereas the total plot yield of fruits varied from 0.15 to $9.38 \mathrm{~kg}$ with a mean of $3.94 \mathrm{~kg}$ only. Total yield per plant varied from 0.15 to 4.69 with an average of $1.61 \mathrm{~kg} /$ plant (Table 3). The entry collected from command area of Plan Office in Makawanpur district produced maximum yield of $4.69 \mathrm{~kg} / \mathrm{plant}$ followed by the entry, collected from Dhankuta (Dhankuta Local) with $4.5 \mathrm{~kg} /$ plant. Yield more than $2 \mathrm{~kg} /$ plant was given by entries Syangja Dalle, Chitwan Local, Pahadiya Local of Nawalparasi collection, Madale Kankro of Kaski and Suryapur Local of Chitwan under the Yampaphant condition.

Table 3. Range and mean values of maturity and yield characters of 25 collection entries tested at Yampaphant, Tanahun, 2000

\begin{tabular}{|c|c|c|c|}
\hline Variables & & Range & Mean \\
\hline Plant stand/plot & 1 & -3 & 2.44 \\
\hline Days to 1 st harvest & 70 & -118 & 99.44 \\
\hline Days to last harvest & 70 & -122 & 102.48 \\
\hline Harvest frequency & 1 & -3 & 1.48 \\
\hline No. of fruits/plot & 1 & -9 & 4.24 \\
\hline Total yield/plot $(\mathrm{kg})$ & 0.15 & $\begin{array}{l}-\quad 9.38 \\
-\end{array}$ & 3.94 \\
\hline Yield/plant (kg) & 0.15 & $\begin{array}{l}-\quad 4.69 \\
\end{array}$ & 1.61 \\
\hline
\end{tabular}




\section{Morphological characters of fruits}

In Table 4 various fruit characters of 15 germplasm entries have been presented. Fruit color has economic importance too. The skin color varied from green, yellow, dark green, black, red to brown while the flesh color from white to yellow; and spine color from white to black. Color stability of fruits varied from low to high. In eleven entries, there were spines whereas other four entries were not having spines on the fruit.

Table 4. Range and mean values of fruit characters of 15 collection entries tested at Yampaphant, Tanahun, 2000

\begin{tabular}{|c|c|c|}
\hline Variables & Range & Mean \\
\hline Skin color & 1 (Green $)-6$ (Brown $)$ & 2.2 \\
\hline Flesh color & 1 (white) $\quad-2($ Yellow $)$ & 1.07 \\
\hline Spine & 1 (present) -2 (Absent) & 1.27 \\
\hline Spine color & 1 (white) $\quad-3$ (Black) & 2.15 \\
\hline Fruit diameter $(\mathrm{cm})$ & -7 & 5.99 \\
\hline Placental hollowness $(\mathrm{cm})$ & -4 & 2.73 \\
\hline Flesh thickness $(\mathrm{cm})$ & -3.1 & 1.95 \\
\hline Seediness & -3 (High) & 1.93 \\
\hline Skin toughness & - 3 (High) & 1.93 \\
\hline Wastyness & - 3 (High) & 1.33 \\
\hline Stripes on fruit & -2 & 1.40 \\
\hline Fruit firmness & 2 (medium) -2 (Medium) & 2 \\
\hline Color stability & - 3 (High) & 1.87 \\
\hline Market acceptability & 1 (acceptable) - 2 ( No acceptable) & 1.33 \\
\hline
\end{tabular}

Fruit diameter varied from 5 to $7 \mathrm{~cm}$ with an average of $5.99 \mathrm{~cm}$. Flesh thickness varied from 1 to $3.1 \mathrm{~cm}$ with an average of $1.95 \mathrm{~cm}$. The diameter of placental hollow varied from 2.2 to $4 \mathrm{~cm}$ with $2.73 \mathrm{~cm}$ as mean. Seediness was from low to high. Skin toughness varied from soft, medium to tough whereas fruit firmness was mostly medium. Wartyness was absent in most of the fruits, whereas 4 entries were having few to medium scale of wartyness. Nine germplasms showed presence of stripes, whereas 4 were devoid of stripes on the fruits. As far as market acceptability of the fruits is concerned, 10 out of 15 germplasm entries were found acceptable, the rest being unacceptable.

\section{Sundarbazar, Lamjung site}

At Sundarbazar, Lamjung site, 138 germplasm entries were tested. Vegetative characters, reproductive characters, fruit yield and quality characters have been presented below.

\section{Leaf characters}

Among vegetative characters studied (Table 5), number of lobes per leaf varied from 4 to 7; leaf color varied from light green to dark green; leaf shape mostly palmate with 7 entries as cordate and one entry as reiniform; almost all the entries were having dense hair on leaf; and tendril type was simple in all the entries. Among the total entries, almost all were having strong tendrils except 13 entries, which were having tendrils with moderate strength.

\section{Stem characters}

As shown in Table 5, main stem length varied from 3.25 to $12.5 \mathrm{~m}$ with an average of $6.34 \mathrm{~m}$. Number of branches per plant varied from 3 to 14 with a mean of 6.5. Number of nodes/plant varied from 58 to 376 with 164 as mean. All the entries were having indeterminate growth habit, light green stem color and dense hair.

\section{Canopy characters}

Table 5 showed that number of leaves/plant ranged from 60 to 380 with a mean value of 170.7. Leaf size varied from small to large, but majority was of having medium sized leaf. Canopy size of all the entries was medium. Number of petals varied from 3.5 to 8.5 with a mean of $6.78 \%$. Flower diameter varied from 2 to 5.6 $\mathrm{cm}$ with $3.81 \mathrm{~cm}$ as mean. 
Table 5. Vegetative characters of cucumber collection entries tested at Sundarbazar, Lamjung, 2000

\begin{tabular}{|c|c|c|c|c|c|}
\hline Variables & No. of entries & Rat & & & Mean \\
\hline No. of lobes/leaf & 138 & 4 & - & 7 & 6 \\
\hline Leaf color & 138 & 1 (light green) & - & 3(Dark green) & 2 (green) \\
\hline Leaf shape & 138 & 1 (palmate) & - & 3 (Rein form) & Mostly palmate \\
\hline Leaf hair density & 138 & 1 (sparse) & - & 2 (dense) & 2 (dense) \\
\hline Tendril strength & 138 & 1 (weak) & - & 3 (Strong) & Mostly strong \\
\hline Main stem length (m) & 69 & 3.25 & - & 12.5 & 6.309 \\
\hline Growth habit & 117 & - & - & - & Indeterminate \\
\hline No. of branches/plant & 69 & 3 & - & 14 & 6.5 \\
\hline Stem color & 69 & - & - & - & light green \\
\hline Nodes/plant & 69 & 58 & - & 376 & 164 \\
\hline No. of leaves/plant & 60 & 60 & - & 380 & 170.7 \\
\hline Leaf size & 123 & 1 (small) & - & 3 (Large) & 1.95 \\
\hline Canopy size & 123 & 1 (small) & - & 2 (Medium) & Medium \\
\hline Flower diameter $(\mathrm{cm})$ & 72 & 2 & - & 5.6 & 3.81 \\
\hline No. of petals & 72 & 3.5 & - & 8.5 & 6.78 \\
\hline
\end{tabular}

\section{Maturity and fruit yield characters}

In Table 6, maturity and yield characters have been presented. Days to first male flower varied from 29 to 88 days with a mean of 54.41 days. Days to first female flower varied from 39 to 111 days with 66.96 days as mean. Total number of female flowers/plot varied from 0 to 28 with a mean of 8.61. Sex ratio varied from 0 to 135.5 with a mean value of 39.40. Days to first fruit harvesting varied from 67 to 110 days with 82.43 days as mean. Likewise, days to last harvest varied from 69 to 110 days with a mean of 88.83 days. The frequency of fruit harvest varied from zero to 4 with 1.49 as mean. Total number of fruits/plot varied from zero to 8 with 2.83 as mean. Likewise, total fruit yield/plot varied from zero to $5.3 \mathrm{~kg}$ with a mean value of $1.54 \mathrm{~kg}$. Total fruit yield/plant varied from 0.0 to $1.77 \mathrm{~kg}$ with a mean value of $0.521 \mathrm{~kg} / \mathrm{plant}$. The entry Green Long, Mahyco produced the highest fruit yield of $1.77 \mathrm{~kg} / \mathrm{plant}$ among the germplasm entries tested at Lamjung. This was followed by the entry Bhaktapur Local, which yielded $1.67 \mathrm{~kg} / \mathrm{plant}$. The other entries producing yield more than $1 \mathrm{~kg} /$ plant were Dadeldhura Local, Nuwakote Local, Tharu Kankro of Dang, Bhaktapur Tumbe and Suryapur Local of Chitwan under Lamjung condition.

Table 6. Range and mean values of maturity and yield characters of various cucumber collection entries at Lamjung site, 2000

\begin{tabular}{|lcccc|}
\hline Variables & No. of entries & Minimum & Maximum & Mean \\
\hline Plant stand/plot & 92 & 1 & 3 & 2.978 \\
Days to first male flower & 85 & 29 & 88 & 54.41 \\
Days to first female flower & 77 & 39 & 111 & 66.96 \\
Total no. of female flowers/plot & 82 & 0 & 28 & 8.61 \\
Sex ratio (male : female) & 58 & 0 & 135.5 & 39.40 \\
Days to 1st harvest & 37 & 67 & 110 & 82.43 \\
Days to last harvest & 37 & 69 & 110 & 82.43 \\
Harvest frequency & 42 & 0 & 4 & 1.49 \\
Total number of fruits/plot & 41 & 0 & 5.3 & 2.83 \\
Total fruit yield/plot (kg) & 41 & 0 & 1.77 & 0.521 \\
Total fruit yield/plant (kg) & 41 & & & \\
\hline
\end{tabular}

\section{Fruit characters}

Various characters related to fruit morphology and quality of 51 germplasm entries have been presented in Table 7. Color variations in fruit skin, fruit flesh and spine were identical at both sites. In 7 entries, the spine was absent. Placental hollowness varied from solid, small, medium to big. Fruit diameter ranged from 4 to 25 $\mathrm{cm}$ with a mean of $12.6 \mathrm{~cm}$. Flesh thickness varied from 0.5 to $3 \mathrm{~cm}$ with a mean of $1.7 \mathrm{~cm}$. Seediness varied 
from low to high. Skin toughness varied from soft, medium to tough. Wartyness varied from none to high degree. Except in 9 entries the color stripes were present on the fruit surface. The color of stripe varied from white to yellow. Fruit firmness was mostly of medium type and so also was the case in respect of color stability of the fruit. Except five germplasms, the rest produced fruits having market acceptability.

Table 7. Fruit characters of various cucumber collection entries tested at Lamjung, 2000

\begin{tabular}{|c|c|c|c|c|}
\hline Variables & No. of entries & Minimum & Maximum & Mean \\
\hline Skin color & 51 & 1 (light green) & 5 (white) & 2.63 \\
\hline Flesh color & 51 & 1 (white) & 4 (yellow) & 1.18 \\
\hline Spines & 51 & 1 (present) & 2 (absent) & Present \\
\hline Spine color & 48 & 1 (white) & 3 (black) & 1.83 \\
\hline Hollowness & 51 & 1 (solid) & 4 (big) & 1.80 \\
\hline Fruit diameter $(\mathrm{cm})$ & 51 & 4 & 25 & 12.60 \\
\hline Flesh thickness $(\mathrm{cm})$ & 46 & 0.5 & 3 & 1.69 \\
\hline
\end{tabular}

\section{Combined analysis of fruit yield of germplasm at both sites}

Table 8 shows the fruit yield of the germplasm entries at both sites. Only ten entries produced fruits at both sites. The highest mean yield of $1.88 \mathrm{~kg} /$ plant was given by a local collection from Suryapur, Chitwan which gave the highest yield of $2.59 \mathrm{~kg} /$ plant and $1.17 \mathrm{~kg} /$ plant at Yampaphant and Lamjung site, respectively. The next local collection from Chitwan gave the second highest mean yield of $1.335 \mathrm{~kg} /$ plant, whereas it was also the second highest at Yampaphant with $2.27 \mathrm{~kg} /$ plant (Table 8); but at Lamjung site, the yield was only 0.4 $\mathrm{kg} /$ plant. Other entries producing mean yield more than $1 \mathrm{~kg} /$ plant were the Arghakanchi Local, Nawalparasi Local (Maker VDC) and Tanahun Local.

Table 8. Fruit yield (kg/plant) of various collection entries at both Lamjung and Yampaphant sites

\begin{tabular}{|c|c|c|c|}
\hline Entry & $\begin{array}{c}\text { Lamjung } \\
\text { (kg/plant) }\end{array}$ & $\begin{array}{c}\text { Yampaphant } \\
\text { (kg/plant) }\end{array}$ & $\begin{array}{c}\text { Mean } \\
\text { (kg/plant) }\end{array}$ \\
\hline Arghakhanchi Local collection & 0.33 & 1.87 & 1.100 \\
\hline Chitwan Local collection & 0.40 & 2.27 & 1.335 \\
\hline Koshi Local collection & 0.27 & 1.47 & 0.87 \\
\hline Pahadiya Local of Nawalparasi collection & 0 & 2.20 & 1.10 \\
\hline Nuwakot Local collection & 0.13 & 0.28 & 0.205 \\
\hline Baitadi Local collection & 0 & 1.96 & 0.980 \\
\hline Tanahun Local collection & 0.50 & 1.70 & 1.10 \\
\hline Nuwakot Wild collection & 0.50 & 0.15 & 0.325 \\
\hline Bhaktapur Local from Palpa & 1.10 & 0.22 & 0.66 \\
\hline Local collection of Suryapur, Chitwan & 1.17 & 2.59 & 1.88 \\
\hline
\end{tabular}

At Yampaphant only, the entries collected from the command area of Plan Office in Makawanpur and Dhankuta Local gave the highest fruit yields of 4.69 and $4.5 \mathrm{~kg} / \mathrm{plant}$, respectively. This can be considered very good yield for off-season production at Yampaphant condition. Similar results were also reported by Subedi, et al. (1997), Pandey and Adhikari (1996) and Seshadri (1998).

At Lamjung site, the yield potentials were comparatively lower than at Yampaphant. None of the entries could exceed fruit yield of $2 \mathrm{~kg} /$ plant. At this site only, the entry Mahyco Green Long gave the highest yield of $1.77 \mathrm{~kg} / \mathrm{plant}$. It was followed by the entry Bhaktapur Local from Butwal with $1.67 \mathrm{~kg} / \mathrm{plant}$, entry Dadeldhura Local with $1.33 \mathrm{~kg} /$ plant, entry Tumbe from Bhaktapur collection with $1.37 \mathrm{~kg} /$ plant and entry Tharu Kankro from Dang with $1.10 \mathrm{~kg} /$ plant and entry Nuwakote Local with $1 \mathrm{~kg} / \mathrm{plant}$. Other remaining entries produced less than one $\mathrm{kg} /$ plant. Those germplasms which gave fruit yields of more than $1 \mathrm{~kg} / \mathrm{plant}$ at each site need to be further tested for confirmation, because it is advisable to record the differential reponse of these lines in 
respect to there sex expession, fruit set and the fruit yield under varied ecological conditions having different temperature and day length (Seshadri, 1990; Lower and Edwards, 1986). Such entries might have high level of resistance to heat for summer-rainy season cultivation in the middle and low hills of Nepal.
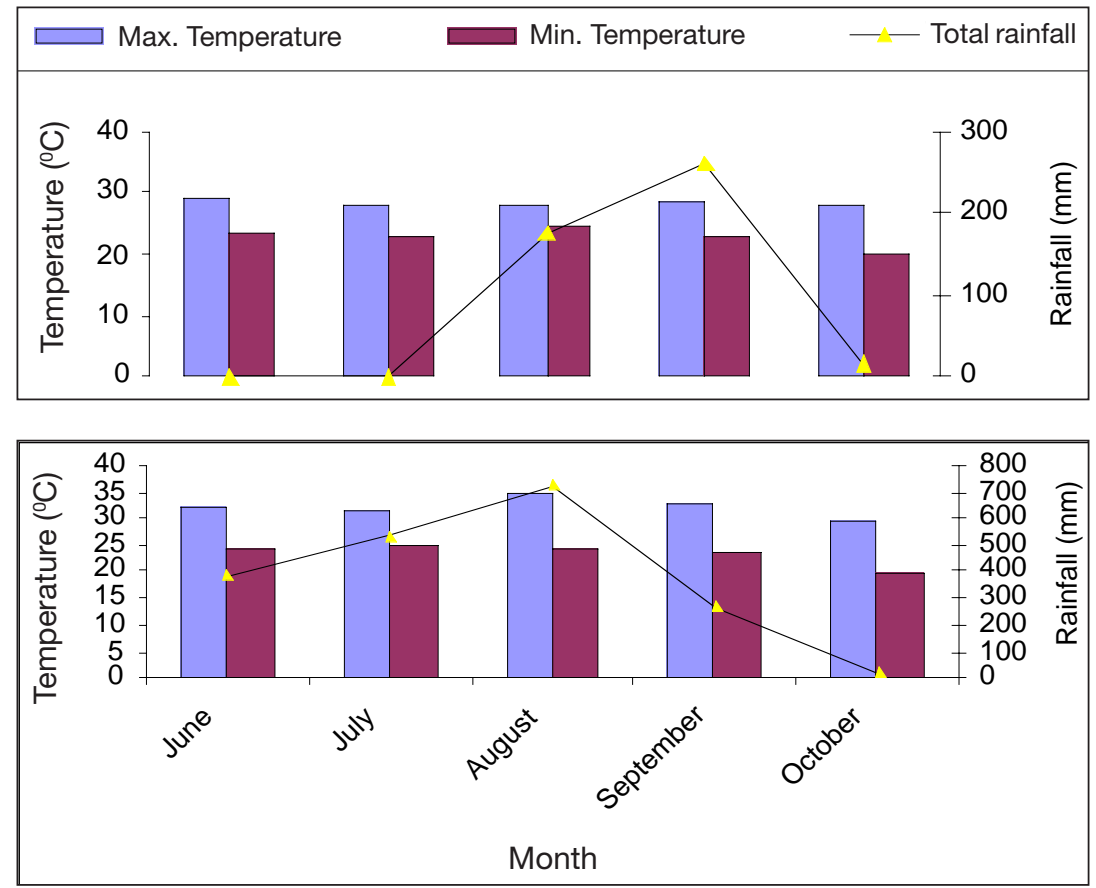

Figure 1. Variation in temperature $\left({ }^{\circ} \mathrm{C}\right)$ and rainfall $(\mathrm{mm})$ during cucumber growing season at Sundarbazar (Lamjung above) and (Yamphaat below)

\section{ACKNOWLEDGEMENTS}

This study was the part of the research project 'Light and temperature induced stress management for off-season cucumber production (HARP105/99)' operated in 1999-2002 under the financial support of the Hill Agriculture Research Project funded by the British Government Department of International Development (DFID).

\section{REFERENCES CITED}

Chaudhary, B. 1987. Vegetables ( $8^{\text {th }}$ Revised Edition). National Book Trust, New Delhi, India. 123 p.

LARC. 1997. The strategy for commercial vegetable research. LARC Strategy Paper No. 97/9, Lumle Agriculture Research Center, Kaski, Nepal.

Lower, R. L. and M. D. Edwards. 1986. Cucumber breeding. In: M. M. Bassett (ed.) Breeding Vegetable Crops. AVI Publ. Inc. pp. 173-204.

Nonnecke, I. L. 1989. Vegetable Production. AVI Book, New York. 645 p.

Pandey, I. R. and K. P. Adhikari. 1996. Research for vegetable development in Nepal. Paper presented at National Seminar on Vegetable Development, 11-12 June 1996. Vegetable Development Division, Kathmandu, Nepal.

Seshadri, V. S. 1990. Cucubits. In: T. K. Bose and M. G. Som (eds.) Vegetable Crops in India. Naya Prokash, India. pp. 91-154.

Shrestha, T. N. and N. P. Ghimire. 1996. Fresh vegetable production in Nepal. Paper presented at National Seminar on Vegetable Development, 11-12 June, 1996. Vegetable Development Division, Kathmandu, Nepal.

Subedi, P. P., S. P. Bhattarai and J. P. Jaiswal. 1997. Increase female flower frequencies of fucumber cv. Bhaktapur local 1996. Working Paper No. 97/28. Lumle Agriculture Research Center, Kaski, Nepal. 